\title{
Layout design criteria for deep tabular mines: Quo vadis?
}

\author{
D.F. Malan ${ }^{1}$ and Y. Jooste ${ }^{2}$ \\ 1Department of Mining Engineering, University of Pretoria, South Africa \\ ${ }^{2}$ Harmony Gold, South Africa
}

\begin{abstract}
This paper describes aspects related to two design criteria used in the deep gold mines of South Africa, namely, average pillar stress (APS) and energy release rate (ERR). Early layout designs were based on trial and error and most of the recommendations of the 1924 Witwatersrand Rock Burst Committee are still valid today. The introduction of APS and ERR assisted greatly in reducing areas of high stress concentrations. Both criteria are of limited use, however, as it is not clear what the maximum value of APS for remnants should be, and ERR has a significant drawback as no dissipative mechanisms are incorporated to allow for rock failure. A numerical modelling study is described that illustrates the effect of total closure on the simulated APS and ERR values of a remnant. It is recommended that stress measurements are conducted below remnant areas to better calibrate the numerical models.
\end{abstract}

\section{INTRODUCTION}

The deep gold mines of South Africa are world famous and more than 50000 tonnes of gold have been extracted from these mines since 1886, Malan (2017). Owing to the great depths of the workings, these mines are seismically active and rockbursts and falls of ground were the cause of many fatalities during the early days of mining. The death rate per 1000 employees per annum caused by falls of ground for the years from 1911 to 1943 varied from 0.72 to 1.2, Jeppe (1946). Compared to modern standards and the guidelines provided by societal risk curves, Joughin (2011), these historic accident rates are not acceptable. The safety record of the mines has improved drastically in recent years and the additional improvement since 2007 is shown in Figure 1. Unfortunately, a number of rockburst accidents at various mines in 2017 and 2018 resulted in an unacceptable loss of life. The increase in the fatality frequency rate in 2017 is shown in Figure 1 and this emphasises the need for further research into methods to mitigate the risk of rockbursts. The production from the gold mines has now also dropped to multidecade lows (See Figure 2). The gold production in 2017 was only 137 tonnes, whereas peak production was 1000 tonnes in 1970. Neingo and Tholana (2016) discussed mining depth and seismicity as a contributor to the recent decrease in production.

Surprisingly, even after a sustained period of production of 132 years, the Witwatersrand Basin is still the world's largest resource of gold, Minerals Council South Africa (MCSA) (2018). Production can therefore continue for many years if the current poor profitability of the mines can be improved and a further improvement in safety can be achieved. Mechanisation is currently being investigated by the South African Mining, Extraction, Research, Development and Innovation (SAMERDI) research programme, as one possible solution. 
The gold industry still employs more than a 100000 workers, MCSA (2018), and the social impact will be profound if most of the affected workers lose their jobs owing to large-scale mine closures in the future.

To achieve sustainability in this sector, an aspect requiring urgent attention is the development of updated design criteria for very deep mines. Remnants and pillars are mined in many of the older operations (See Figure 3) and most of these extractions are done safely. There is currently, however, a great need to improve the criteria used to select which remnants can be mined safely. As shown in this paper, most of the design criteria currently used is based on elastic theory and the failure of the rock mass is not taken into account. Total closure in some of the older mines also appears to de-stress some of the remnants, but there is no current methodology to objectively quantify this effect on a mine-wide scale. These aspects require urgent research, but surprisingly, there seems to be little appetite from some mining companies and the controlling bodies to fund fundamental research on design criteria and rock mass behaviour. A notable exception is Harmony Gold, currently funding the Harmony Gold Research Chair in Rock Mechanics in the University of Pretoria. A specific aspect addressed by this research is the effect of mining rate.

The objective of this paper is to illustrate the shortcomings of the existing design criteria used in the deep South African gold mines and to illustrate some avenues of research that may lead to improvements in the layouts and better hazard identification. Van der Merwe (2006) used the Coalbrook disaster as an example of lessons not learnt from accidents and deplored the dismal state of rock engineering research in South Africa. He stated: "Is it conceivable that the most important lesson from Coalbrook, namely that in order to be effective at all, knowledge has to be generated before it is needed, was not learnt?" Twelve years after this paper was written, rock engineers still grapple with which are the most appropriate design criteria to use when doing remnant extraction, but only very limited research on this topic was done during the period. This paper highlights the shortcomings of the current design criteria and it will hopefully motivate the funding of additional research in this area.

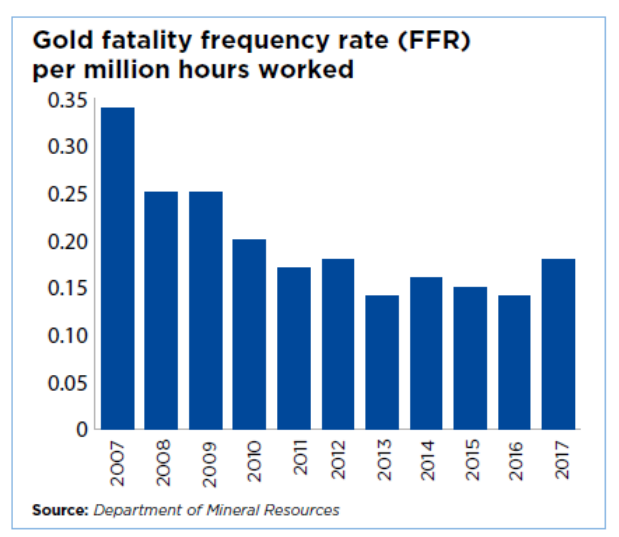

Figure 1. Fatality frequency rate in the South African gold mines from 2007 to 2017 (Courtesy, Minerals Council South Africa, 2018) 


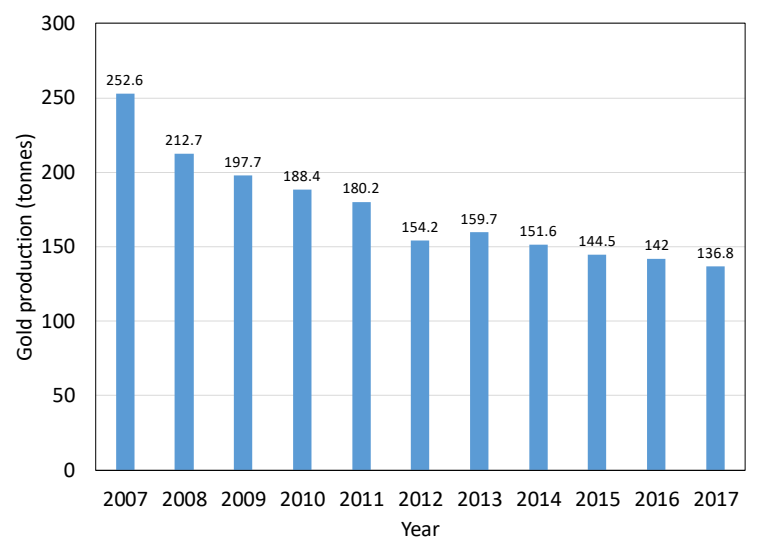

Figure 2. South African gold production from 2007 to 2017(Courtesy, Minerals Council South Africa, 2018)

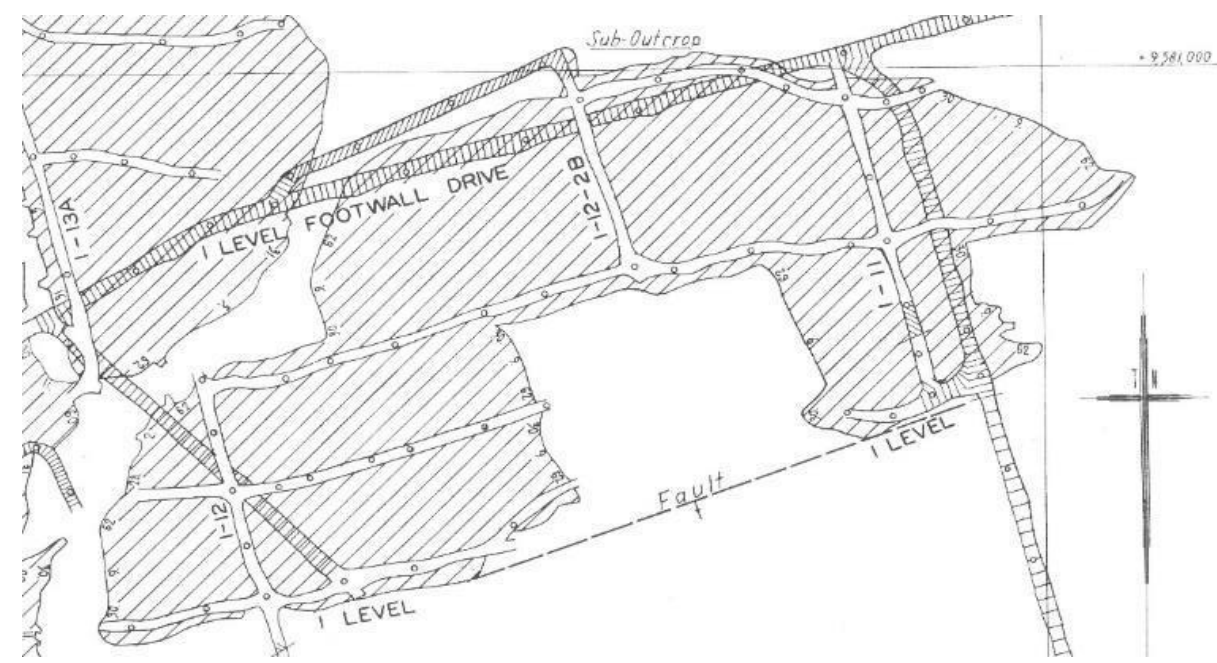

Figure 3. A remnant (the square block above the fault) that was successfully extracted at Doornfontein Mine in 1962. The face on the east was stopped and the face on the west was mined using hydraulic props and caving in the back area (Hinds,1963)

\section{OVERVIEW OF THE EVOLUTION OF ROCK ENGINEERING DESIGN CRITERIA IN THE GOLD MINING INDUSTRY}

Durrheim (2010) gave a comprehensive overview of the risk of rockbursts in deep, hard rock mines. The first damage on surface was reported as early as 1908 and the Ophirton Earth Tremors Committee was appointed to investigate the early stress-related problems in the mines. The committee concluded that "the pillars are severely strained; that they partly give way suddenly..." and recommended that the pillars be replaced by waste packs. This study was followed by the appointment of the 1915 Witwatersrand Earth Tremors Committee which concluded: "The removal of reef or reefs over large areas throws the weight of superincumbent mass on the unexcavated portions or pillars which, when the depth reaches 1,000 feet or more, are unable to bear the weight and are crushed. When crushing takes place suddenly, a rock burst occurs and causes a tremor." The committee recommended the removal of the pillars if they were unable to carry the load or the use of sand filling in adjacent areas if the pillars could not be removed. The 1924 Witwatersrand Rock Burst Committee made several practical suggestions regarding layouts, Jeppe (1946). The following are direct quotes of the suggestions from this source, although the exact meaning is not clear in all cases: 
- The ore should be extracted as completely as possible in the first working; pillars or remnants of reef should not be left where that is avoidable.

- Efforts should be made to avoid the formation of isolated areas of reef, and to that end stoping should be kept well advanced on the mine boundaries.

- Stoping should be concentrated at the bottom of the mine so far as practicable.

- When two reefs are being mined one should be worked out as completely as possible in advance of the other.

- Large shaft pillars should be left for vertical shafts.

- Main levels should be a considerable distance in the footwall, and should be stoped over;

In terms of remnants it was suggested:

- The working face should be advanced rapidly and continuously.

- Ample support of a character that will stand shocks should be kept close up to the working face.

- The minimum number of persons necessary should be employed near the working face.

- The direction of the working face should be carefully selected with a view to safety.

- The hanging wall portion of the face should be kept advanced.

- Stope pillars should not be cut.

Current rock engineers in the industry will recognise that most of these 1924 recommendations are still being used in industry. Close scrutiny of these empirical rules indicated that it worked in 1924 because it reduced excessive stress concentrations. None of the earlier workers described the problem in terms of quantitative values of stress, however, as no practical techniques existed to estimate stress levels in irregular mining layouts.

To avoid the formation of remnants, the longwall stoping method was recommended by the 1924 Rockburst Committee. It was first introduced on Crown Mines in the 1930s where the longwall faces were carried in an overhand configuration. This consisted of a longwall covering 3 levels and the number of remnants was reduced to one instead of three Jeppe (1946). This was later changed to the longwall peak stoping method where the faces where carried in underhand configuration, but this method was discontinued in 1944. In 1942 two underhand longwall stopes were successfully introduced in the Hercules section of ERPM as part of an experiment to reduce rockbursts, Hill (1944). This layout is shown in Figure 4. It was shown that this resulted in: "A large reduction in the incidence and severity of pressure bursts." Apparently, the number of rockbursts decreased from 35 in 1941 to 14 in 1943. Longwalls were unfortunately not perfect as grade control was a problem and it was difficult to use this layout in areas with a large number of faults and dykes.

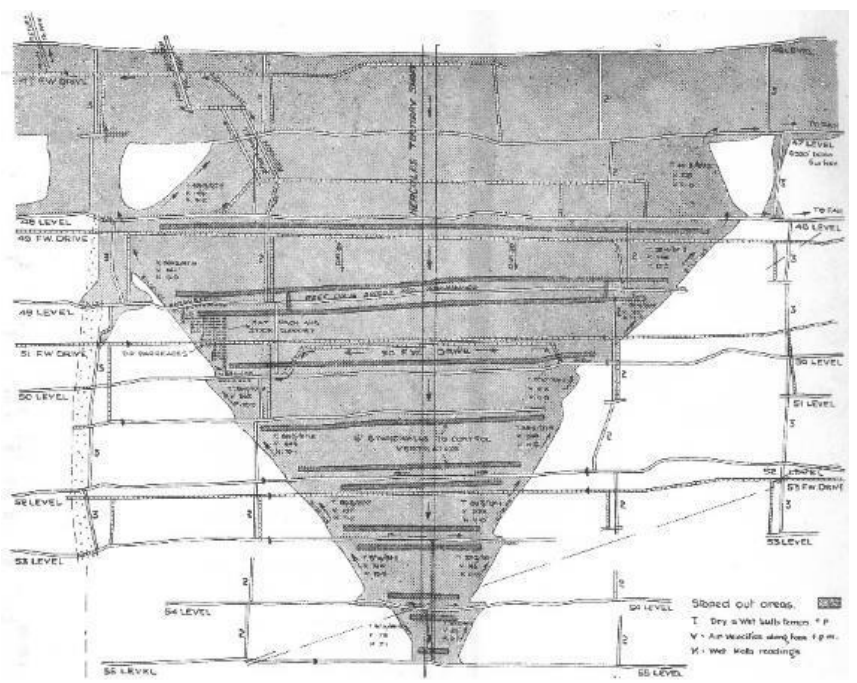


Figure 4. The Hercules longwall section at ERPM in December 1943

Although these empirical techniques resulted in a reduction and severity of rockbursts, Cook et al (1966) wrote that by 1950: "It become painfully clear that that progress was reaching a standstill". A more fundamental approach was required. To further mitigate the rockburst problem, the CSIR was approached and in 1953 the Chamber of Mines undertook to sponsor research in rock mechanics. A committee composed of Chamber staff, the mining groups and the CSIR then guided research over a number of years. Assistance from the Bernard Price Institute of Geophysical Research and the University of the Witwatersrand was also obtained. The research advisor of the Chamber of Mines was appointed in 1962 and the Chamber of Mines Research Laboratory was established. Cook et al (1966) summarised the progress that was made as a result of these efforts. A key breakthrough was that the far field rock mass behaviour could be approximated by elastic behaviour, Ryder and Officer (1964). Cook et al (1966) summarised the progress as follows: "The paper produces evidence to show that the unfractured rock strata behave elastically, while seismic observations have confirmed the close relationship that exist between active mining operations and releases of energy. Indeed, the problem is shown by the authors to revolve around the concepts of energy release and energy dissipation and they suggest that further progress in lessening the incidence and severity of bursts can best come about through either reducing the release of energy or increasing the dissipation of energy in non-violent form." This work was indeed a major breakthrough and in the decades that followed, strategies such as the introduction of stabilising pillars, backfill, numerical modelling of layouts to reduce the ERR and bracket pillars to clamp geological structures, were all based on the foundation laid by this research.

In the gold mines, the current rockburst mitigation strategies can be broadly classified into two groups. The first set of measures attempts to reduce the occurrence of the number of damaging seismic events, especially when there are workers in the stopes. These include layouts to minimise stress concentrations, bracket pillars to prevent slip on geological structures, centralised blasting systems and preconditioning. Measures are also implemented to protect the workers during rockbursts and this involves the installation of rockburst resistant support with energy absorbing capabilities. A key aspect of the first part of the strategy is to minimise excessive stress concentrations. This is currently achieved by numerical modelling of the layouts and applying the two key design criteria, namely, average pillar stress (APS) and energy release rate (ERR). Of significance is that these two criteria are imperfect criteria as they do not take into account the extensive stress-related fracturing of the rock mass that is so ubiquitous in these deep mines. Other forms of inelastic behaviour, such as total closure, are also ignored by these two parameters. As many of the older mines exploit remnants, the question should be asked if these criteria are still valid in the remnant areas and if not, what alternative method should be used to better estimate the stress distribution and associated hazards in these areas. Modelling of a simplified remnant geometry is included in this paper to illustrate the value of stress measurements to better identify areas of high stress concentrations. The third key design criterion, excess shear stress (ESS) on geological structures, is not considered in this paper.

\section{AVERAGE PILLAR STRESS}

A difficult problem faced by engineers in the mining industry is to evaluate if remnants can be mined safely and the stress acting on these remnants needs to be estimated. The computation of average pillar stress (APS) values is also important when attempting to establish criteria for pillar design and in the analysis of the stability of tabular pillar layouts, Ryder and Jager (2002). Pillars with a width to height ratio exceeding 10:1 are often assumed to have infinite strength, although this ignores possible foundation failure, Ryder and Jager (2002). Foundation failure, which involves rupture along planes in previously intact rock, needs to be considered for highly-stressed remnants and large pillars. In the deep gold mines, pillar foundation failure of the regional pillars is of particular concern as these can generate seismic events in excess of magnitude 3. Some of the early work on this mode of failure was done by Wagner and Schumann (1971). They conducted laboratory tests in which the bearing strength of rock loaded with a circular stamp was investigated. They concluded that for larger stamp diameters, the bearing strength of the rock is approximately four times the uniaxial compressive strength of the 
rock. To avoid this type of failure, a commonly used empirical rule is, Ryder and Jager (2002):

$$
\text { Design } A P S \leq f_{a} \sigma_{c} \text {, }
$$

where $\sigma_{c}$ is the uniaxial compressive strength (UCS) of the foundation strata. This is the weakest of the hanging wall or footwall strata and $f_{a}$ is an empirical factor typically taken as 2.5. This empirical factor is the controversial part of this criteria as Wagner and Schumann (1971) estimated a value as high as 4 from the laboratory testing. The value of 2.5 was suggested in the 1988 Rockfalls and Rockburst guide Chamber of Mine Research Organisation (1988). As stated in the guide: "Laboratory tests suggest that foundation failure occurs if the average pillar stress (APS) exceeds the uniaxial strength of the host rock by approximately 3.5 times...Thus in practice, due to the presence of rock mass weaknesses and uncertainties regarding virgin horizontal stress levels, a factor of no more than 2.5 should be used." This is unsatisfactory as no scientific reason is given for this value of 2.5. Jager and Ryder (1999) refer to it as "An approximate and conservative criterion,". In contrast, Ryder and Jager (2002) reported work by Handley that back area pillar seismicity may start at values as low as 1.2. This was confirmed by FLAC modelling with a strain softening model which indicated that the APS should be limited to 1.25 times the UCS. Based on these studies, it is clear that further modelling work and field experiments needs to be done.

To compound this problem, a numerical modelling quirk may result in erroneous APS calculations. Although the APS can readily be estimated using tributary area theory for regular layouts, the evaluation of equation 1 in practice requires that the pillar stress be computed for irregular layouts. One of the popular numerical methods that is used to determine pillar stresses in the gold mining industry, is the displacement discontinuity method. In many instances it is not understood that this approach suffers from limitations. In coarse element simulations, the results can depend on the chosen element mesh size. This was investigated by Napier and Malan (2011), and more accurate pillar stress estimation can be obtained by calculating two APS values by using different grid sizes and then to calculate the extrapolated APS value as the grid size tends to zero (See Figure 5).

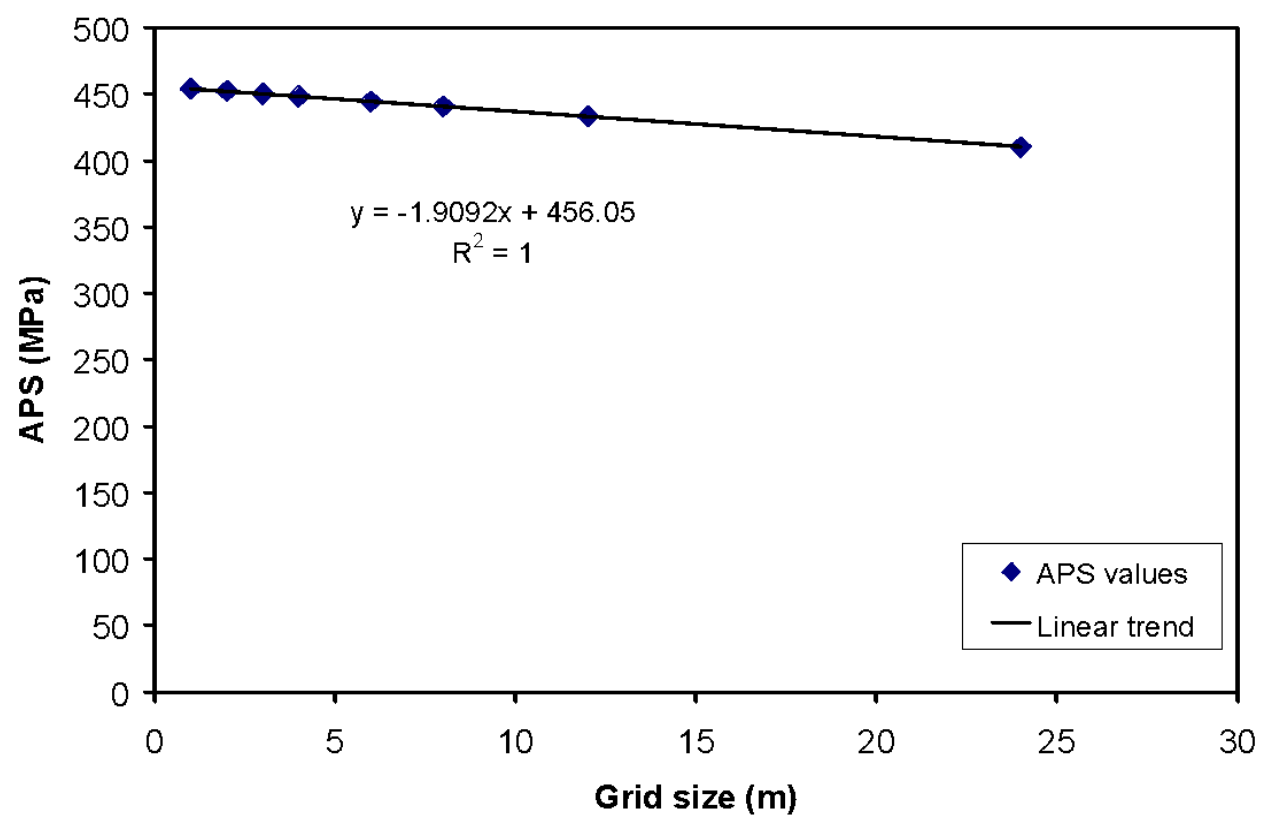

Figure 5. Average stress magnitude estimates for a single pillar as a function of the element grid size (Panel span, $S=120 \mathrm{~m}$; central pillar width, $W=24 \mathrm{~m}$ ) (Napier and Malan, 2011)

The linear trend displayed in Figure 5 suggests that if two APS values of $A_{1}$ and $A_{2}$ are found, corresponding to grid size values of $\mathrm{g}_{1}$ and $g_{2}$ respectively, then the extrapolated value (for the APS 
limit as the grid size tends to zero) can be estimated from the equation

$$
A=\frac{A_{2} g_{1}-A_{1} g_{2}}{g_{1}-g_{2}}
$$

In the special case where $g_{2}=g_{1} / 2$, equation 2 reduces to

$$
A=2 A_{2}-A_{1},
$$

where $A_{2}$ corresponds to the APS value of the finer grid size.

A further complication associated with APS calculations, is also frequently encountered in deep gold mines. Owing to the tabular nature of the orebody and the small mining height, total closure (contact between hanging wall and footwall) can occur in some areas (See Figure 6 and Figure 7). The resulting regeneration of stress in these old areas results in a reduction of stress on the remaining remnants. There is, however, no reliable method to determine the extent of total closure on the reef horizon. Physical access to the old mining areas is frequently not possible and numerical modelling can only be used if it accurately reflects the inelastic rock failure and associated increase in deformation around the excavations on a mine wide-scale. The modelling of off-reef failure on a mine-wide scale cannot be done with the existing tools. An interim solution proposed by Gürtunca and Adams (1991), was to use elastic modelling with a reduced Young's modulus (E). This is an unsatisfactory solution and one of the problems is that calibration of this reduced modulus, is extremely difficult. Numerical modelling of the remnant shown in Figure 6 indicated an APS value of $733 \mathrm{MPa}$ when using a value of E $=70 \mathrm{GPa}$. Such a high APS did not exist in practice as the remnant was extracted safely and no large seismic events were recorded during this extraction. A more practical method to determine pillar APS would be to use overcoring stress measurements techniques and these are occasionally used in the industry. The high cost and difficulty in obtaining intact cores in highly stressed pillar areas unfortunately prevent the large-scale use of this technique.

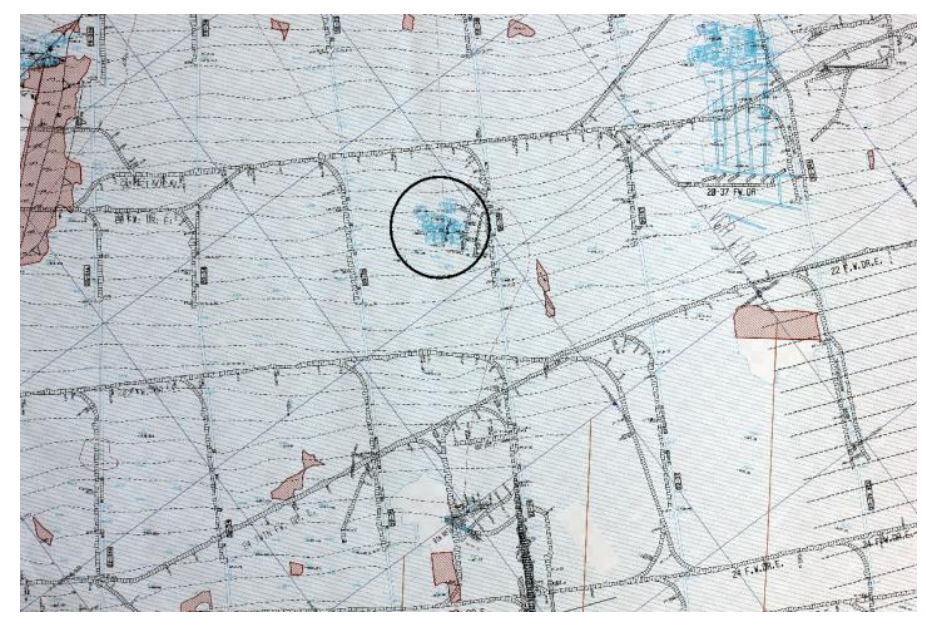

Figure 6. Example of a mining area with a high extraction ratio. The spacing of the gridlines is $200 \mathrm{~m}$. The blue hatched area is mined out and the red areas are the remaining reef remnants. The blue remnant shown in the circle was safely extracted, although the elastic modelling erroneously indicated a very high APS value of $733 \mathrm{MPa}$ 

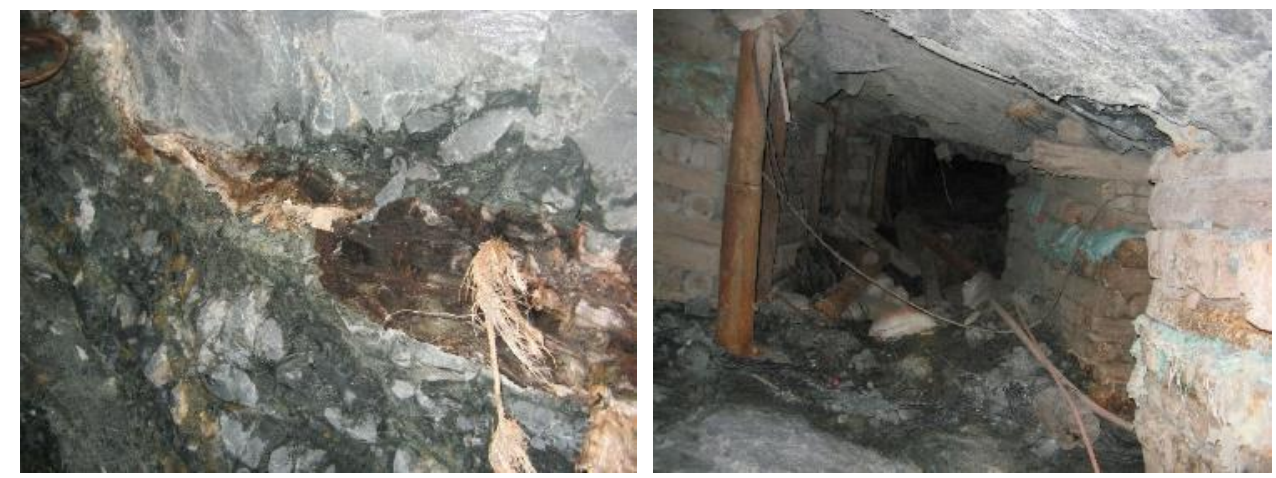

Figure 7. Photographs illustrating the typical mining conditions in the remnants shown above. The photographed on the left illustrates the holing into the old mining area. Total closure occurred as seen by the compressed pack (brown patch in the face). The photograph on the right illustrates the low rate of closure in the remnant in spite of a very high simulated APS value

\section{NEW DEVELOPMENTS IN TERMS OF ENERGY RELEASE RATE}

A common criterion that is used in the design of the deep level gold mine layouts, is the energy release rate (ERR); Cook (1963), Heunis (1980). In the definition of this criterion, the energy release increment, $\Delta W_{A}$, represents the difference between the incremental work done by gravity forces acting on the rock mass, $\Delta W$, and the incremental change in the strain energy, $\Delta U$, that is stored in or released from the rock mass when mining an increment, Napier and Malan (2014). This is given by:

$$
\Delta W_{A}=\Delta W-\Delta U
$$

For the tabular excavations, the mining increment is typically expressed in terms of the area mined with respect to the plan view of the stope. If the incremental area mined is designated by $\Delta A$, then the energy release rate is given as

$$
E R R=\lim _{\Delta A \rightarrow 0} \frac{\Delta W_{A}}{\Delta A}
$$

For practical ERR calculations, stress analysis programmes based on the displacement discontinuity boundary element method is typically used, Plewman et al (1969), Deist et al (1972) and Ryder and Napier (1985). The excavation is approximated as a narrow slit and in many applications the reef material is assumed to be rigid and to have infinite strength. The use of ERR as a criterion for layout design has been extensively discussed. It has a number of practical shortcomings as a measure of the rockburst hazard, Salamon (1984) and Napier (1991). The most significant drawback of the ERR criterion when used with the elastic models is that no dissipative mechanisms are incorporated to allow for local on-reef failure. Equation 5 represents the local value of the energy release at each point of the tabular excavation boundary and can be used as a measure of the local stress concentration at the stope face. An improved measure of stability can be obtained by modifying equation 4 to include an energy dissipation term $\Delta W_{D}$. A general measure of incremental mining stability, designated as $\Delta W_{R}$, can then be defined to be:

$$
\Delta W_{R}=\Delta W_{A}-\Delta W_{D}
$$

The incremental stability measure, defined by equation 6, is associated with each incremental change to the excavation shape. It can also include released energy from explicitly modelled faults or other discontinuities. Napier and Malan (2018) proposed that the fracture zone adjacent to the edges of tabular 
excavations can be represented by a simple time-dependent limit equilibrium model. In this case, the energy dissipation term $\Delta W_{D}$ can be computed explicitly in a series of discrete time steps with imposed face advance increments corresponding to a given mining schedule.

\section{THE EFFECT OF TOTAL CLOSURE ON ERR AND APS}

As a simple illustration of the effect of total closure on ERR and APS, a remnant geometry was simulated with the TEXAN code, Napier and Malan (2007). The geometry consisted of a single remnant of size $40 \mathrm{~m} \times 40 \mathrm{~m}$ in a total mined area of $400 \mathrm{~m} \times 400 \mathrm{~m}$ (See Figure 8). This remnant was simulated at a depth of $1000 \mathrm{~m}$ with various values of Young's modulus to simulate different areas of total closure adjacent to the remnant. The Poisson's ratio in all cases were 0.2 , and the stoping width was $1 \mathrm{~m}$. The code can simulate the effect of total closure, so when the closure becomes equal to the stoping width (1000 $\mathrm{mm}$ in this case), stress is regenerated in the area of total closure. The square displacement discontinuity element sizes were $2 \mathrm{~m}$ for these models.

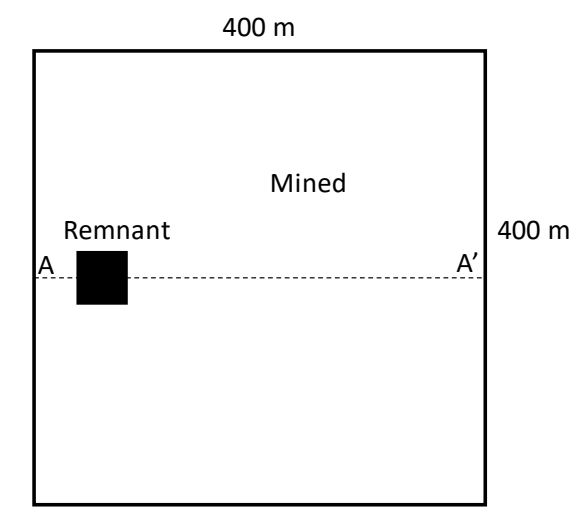

Figure 8. Geometry used to investigate the effect of total closure on APS and ERR

Figure 9 illustrates the area of total closure for the specific case of $\mathrm{E}=10 \mathrm{GPa}$. This results in the regeneration of stress of more than $12 \mathrm{MPa}$ in the centre portion of the mined stope (See Figure 10). Figure 11 illustrates the decrease in APS on the remnant for an increase in the area of total closure. The APS on the remnant decreases from $174 \mathrm{MPa}$ for no total closure to $119 \mathrm{MPa}$ at the lowest value of $\mathrm{E}$. Based on these elementary results, it is clear that elastic modelling may over-estimate the stress acting on remnants in old mining areas with large mining spans when inappropriate values of $\mathrm{E}$ are used. Figure 12 illustrates the corresponding decrease in average ERR values for the remnant (calculated for the remnant face adjacent to the large area of total closure). 


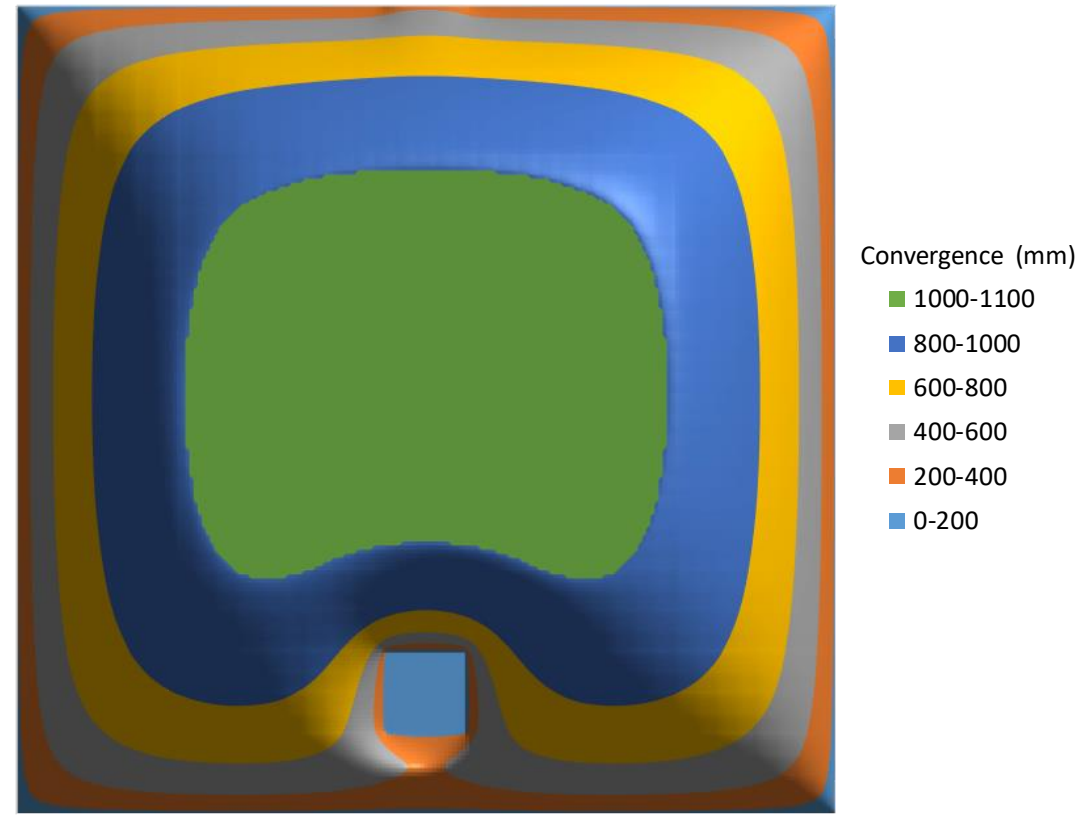

Figure 9. Simulated area of total closure (green centre) for $E=10 \mathrm{GPa}$. Note that this figure is rotated by $90^{\circ}$ when compared to Figure 8

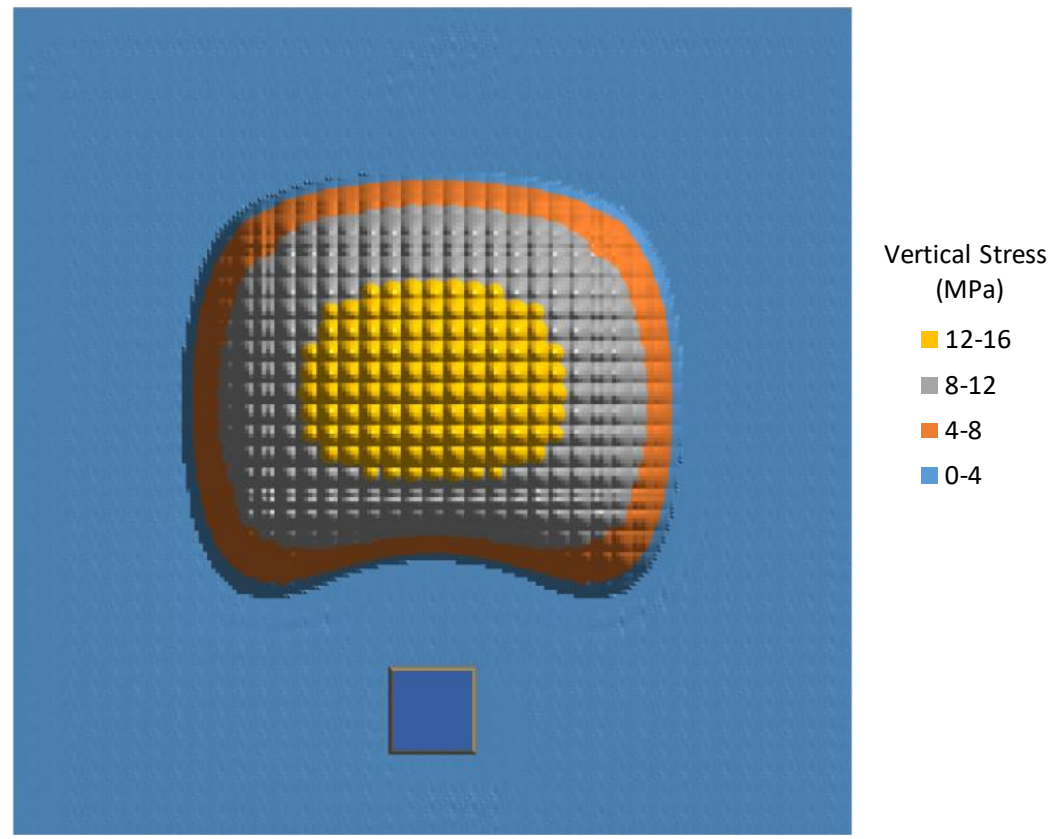

Figure 10. Simulated stress regeneration in the area of total closure for $E=10 \mathrm{GPa}$. Note that this figure is rotated by $90^{\circ}$ when compared to Figure 8 


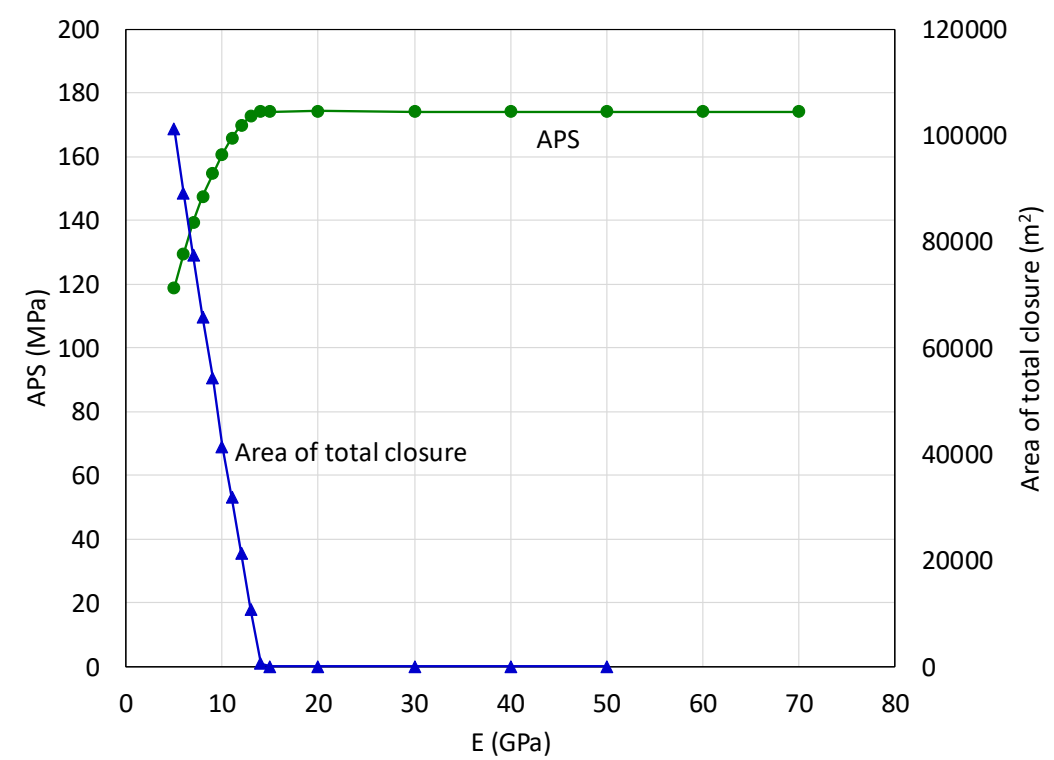

Figure 11. APS of the remnant and the area of total closure for various values of $E$

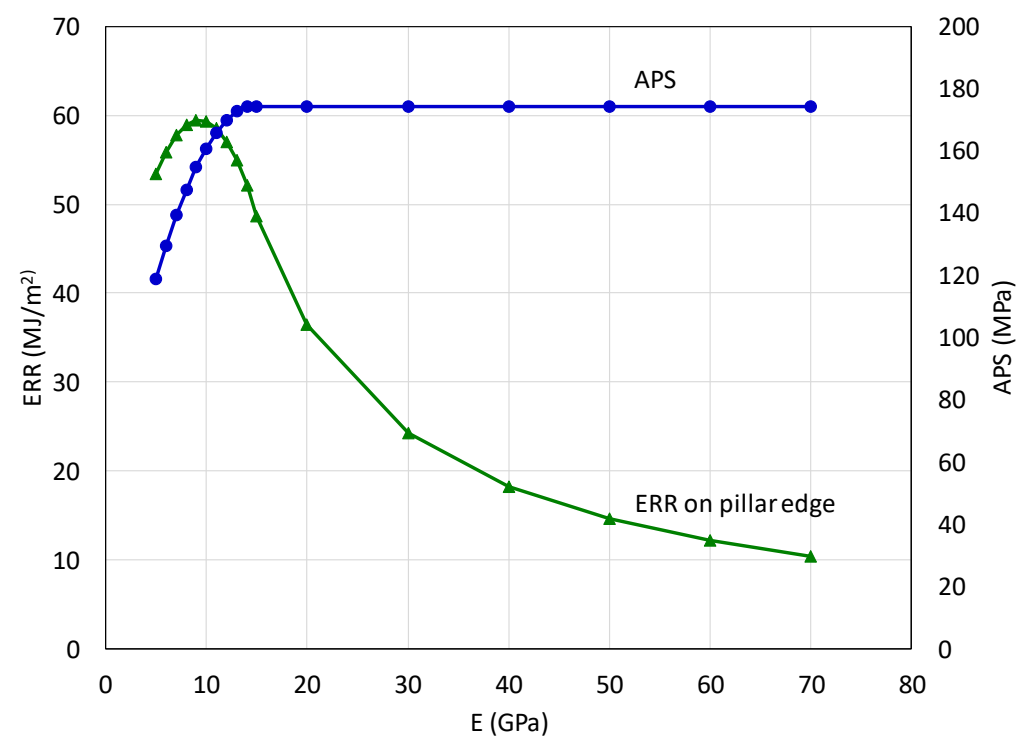

Figure 12. APS of the remnant and ERR (adjacent to the large span) as a function of $E$

\section{STRESS MEASUREMENTS TO CALIBRATE NUMERICAL MODELS}

It is clear from the modelling in the previous section that it is very difficult to accurately model pillar or remnant stress in areas where total closure occurred. Because of the difficulty of accessing the old areas, a size estimate of the area of total closure is not possible. A possible solution would be overcoring stress measurements in the footwall haulages below these areas and using this data to calibrate the numerical models. Figure 13 and Figure 14 illustrate the vertical stress along line AA (See the geometry in Figure 8 ) at depths of $50 \mathrm{~m}$ and $100 \mathrm{~m}$ below reef. The effect of the remnant is clearly visible at $50 \mathrm{~m}$ below reef, but not at $100 \mathrm{~m}$ below reef. The vertical stress in the middle of the mined span increases substantially as the amount of total closure increases. A possible solution to more accurately simulate the actual stress on the remnant would be to do stress measurements in the remnant areas and then adjust the $E$ value to match the measured stress values in the footwall more accurately. If there are areas of total closure, the measured vertical stress below this area will be higher and the stress on nearby 
remnants on the reef plane will be lower. Numerical modelling and actual stress measurements are required to quantify this effect.

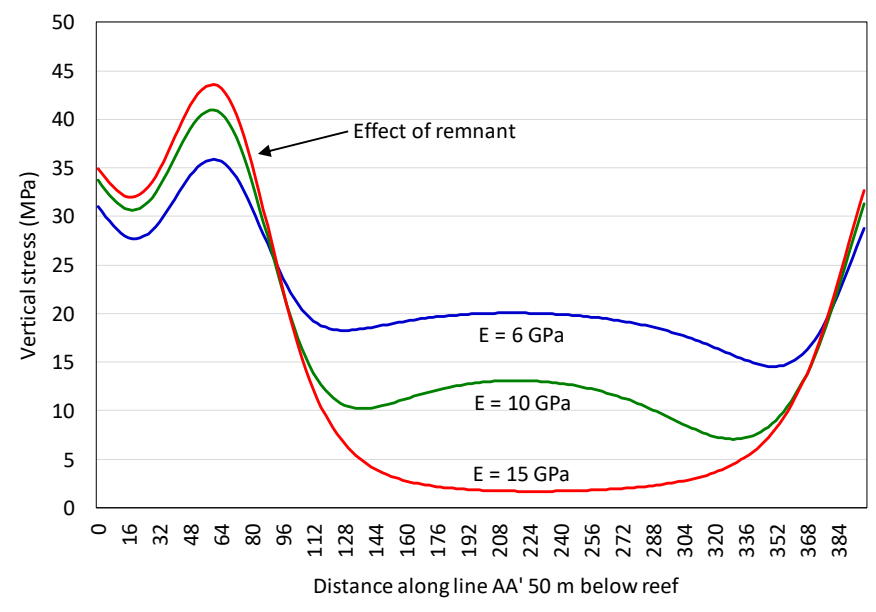

Figure 13. Vertical stress along line $A A^{\prime}$ (Figure 8) at a depth of $50 \mathrm{~m}$ below reef for various values of $E$. For this geometry and parameters, total closure only occurs at values of $E<15 \mathrm{GPa}$

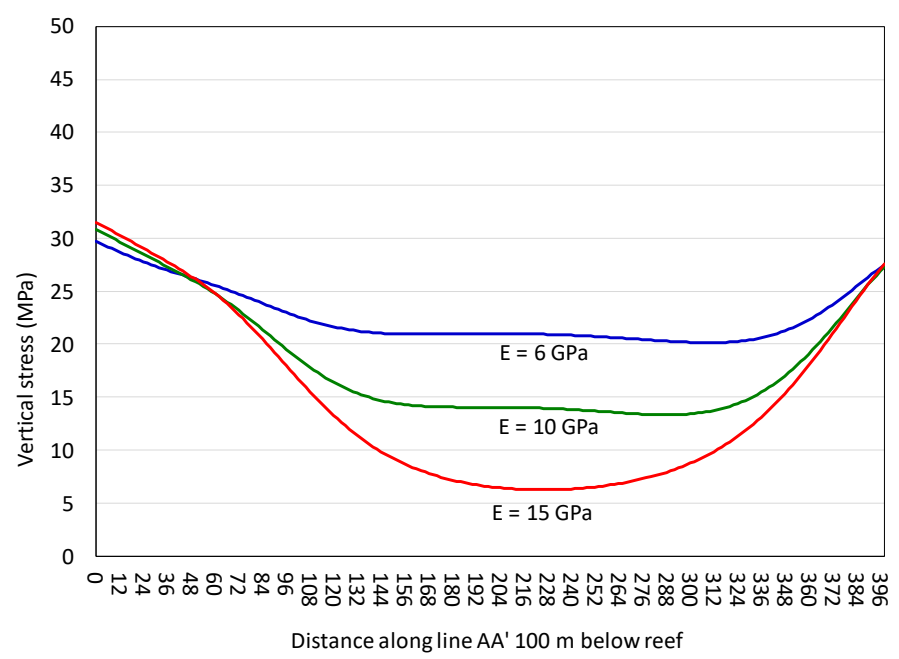

Figure 14. Vertical stress along line AA' (Figure 8) at a depth of $100 \mathrm{~m}$ below reef for various values of $E$. For this geometry and parameters, total closure only occurs at values of $E<15 \mathrm{GPa}$

\section{CONCLUSION}

This paper investigated aspects related to two of the design criteria used in the deep gold mines of South Africa, namely, average pillar stress (APS) and energy release rate (ERR). The early layout designs in the gold mines were based on trial and error and of interest is that most of the recommendations of the 1924 Witwatersrand Rock Burst Committee are still valid in modern times. The introduction of APS and ERR assisted greatly in reducing areas of high stress concentrations. Both criteria are of limited use, however, as it is not clear what the maximum value of APS on remnants and pillars should be and ERR has a significant drawback in that no dissipative mechanisms are incorporated to allow for on-reef failure. A numerical modelling study is described in the paper that illustrate the effect of total closure on the simulated APS and ERR values of a remnant. It is recommended that actual stress measurements 
are conducted below remnant areas to better calibrate the numerical models.

\section{ACKNOWLEDGMENTS}

This work forms part of a PhD study undertaken by Yolande Jooste in the University of Pretoria. This work is also an example of some of the work done by the Harmony Gold Chair of Rock Engineering. The authors would like to thank Harmony Gold for permission to include this work in the paper.

\section{REFERENCES}

Chamber of Mines Research Organisation (1988). An industry guide to methods of ameliorating the hazards of rockfalls and rockbursts.

Cook, N.G.W. (1963). The basic mechanics of rockbursts. Journal of the Southern African Institute of Mining and Metallurgy. 64:71-81.

Cook, N.G.W., Hoek, E., Pretorius, J.P.G., Ortlepp, W.D., and Salamon, M.D.G. (1966). Rock mechanics applied to the study of rockbursts. Journal of the Southern African Institute of Mining and Metallurgy. 66: 435-528.

Deist, F.H., Georgiadis, E. and Moris, J.P.E. (1972). Computer applications in rock mechanics. Journal of the Southern African Institute of Mining and Metallurgy 72:265-272.

Gürtunca, R.G., and Adams, D.J. (1991). Determination of the in situ modulus of the rockmass by the use of backfill measurements. Journal of the Southern African Institute of Mining and Metallurgy, 91(3), 81-88.

Heunis, R. (1980). The development of rock-burst control strategies for South African gold mines. Journal of the Southern African Institute of Mining and Metallurgy 80:139-150.

Hill, F.G. (1944). A system of longwall stoping in a deep level mine with special reference to its bearing on pressure bursts and ventilation problems. Association of Mine Managers of South Africa - Papers and discussions 1942-1945 Vol.1. 257-276.

Hinds, C.G. (1963) The extraction of a remnant using mechanical props as a means of support, Association of Mine Managers of South Africa - Papers and discussions 1962-1963 Vol.1. 497-510.

Jager, J.A. and Ryder, A.J. (1999). A handbook on rock engineering practice for tabular hard rock mines, SIMRAC, Johannesburg.

Jeppe, C.B. (1946). Gold Mining on the Witwatersrand Vol. II. The Transvaal Chamber of Mines.

Joughin, N.C. (2011). Engineering considerations in the tolerability of risk. Journal of the Southern African Institute of Mining and Metallurgy, 111: 535-540.

Malan, D.F. (2016). Krugerrand - Golden Jubilee. Prestige Bullion, The South African Mint and Rand Refinery, Johannesburg.

Malan, D.F. and Napier, J.A.L. (2018). Rockburst support in shallow-dipping tabular stopes at great depth. International Journal of Rock Mechanics and Mining Science, 112: 302-312.

Minerals Council South Africa (2018). Facts and Figures 2017.

Napier, J.A.L. (1991). Energy changes in a rockmass containing multiple discontinuities. Journal of the Southern African Institute of Mining and Metallurgy: 91:145-157.

Napier, J.A.L. and Malan, D.F. (2014). A simplified model of local fracture processes to investigate the structural stability and design of large-scale tabular mine layouts. In: 48th US Rock Mechanics / Geomechanics Symposium, Minneapolis, USA. 
Napier, J.A.L. and Malan D.F. (2018). Simulation of tabular mine face advance rates using a simplified fracture zone model. International Journal of Rock Mechanics and Mining Sciences 109:105-114.

Neingo, P.N. and Tholana, T (2016). Trends in productivity in the South African gold mining industry. Journal of the Southern African Institute of Mining and Metallurgy, 116: 283-290.

Plewman, R.P., Deist, F.H. and Ortlepp, W.D. (1969). The development and application of a digital computer method for the solution of strata control problems. Journal of the Southern African Institute of Mining and Metallurgy 70:33-44.

Ryder, J.A. and Jaeger, A.J. (2002). A textbook on rock mechanics for tabular hard rock mines. SIMRAC.

Ryder, J.A. and Napier, J.A.L. (1985). Error analysis and design of a large-scale tabular mining stress analyser. In: 5th International Conference on Numerical Methods in Geomechanics, Nagoya, Japan: 1549-1555.

Ryder, J.A. and Officer, N.C. (1964). An elastic analysis of strata movement observed in the vicinity of inclined excavations. Journal of the Southern African Institute of Mining and Metallurgy, 64(6): 219244.

Salamon, M.D.G. (1984). Energy considerations in rock mechanics: fundamental results. Journal of the Southern African Institute of Mining and Metallurgy. 84:233-246.

Wagner, H. and Schumann, E.H.R. (1971). The stamp-load bearing strength of rock - An experimental and theoretical investigation. Rock Mechanics. 3:185-207.

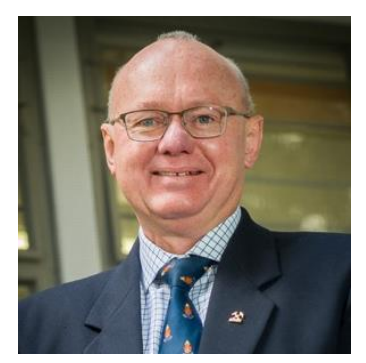

\section{Daniel Francois Malan}

Professor

University of Pretoria

Prof Malan started his career at the Chamber of Mines Research Organisation (COMRO and later CSIR Miningtek) in 1993 and conducted research on the rock mass behaviour in deep tabular mines. His particular interest during this period was the time-dependent behaviour of the rock. He used as topic for his PhD thesis and this later won him the ISRM Rocha Medal in 2001. Prof Malan started as principal researcher, and later became project manager, Research Area Manager and Programme Manager of the Rock Engineering Programme. To gain more experience in industry, Prof Malan joined Groundwork Consulting in 2004. In 2011, he was appointed as Senior Consultant Rock Engineering of Gold Fields in South Africa. The Gold Fields mines were taken over by Sibanye in 2013. Prof Malan remained with Sibanye. In 2018, he joined the University of Pretoria as Associate Professor. 